\title{
Synthesis of Zinc Coneflower-Porous Starch composite for textile finishing
}

\author{
Nitisha Mehrotra ${ }^{1,3} \cdot$ Uma Venkatraman $^{1} \cdot$ V. Chaitra $^{1} \cdot$ N. S. Kaviyarasi ${ }^{2} \cdot$ N. Pradeep $^{1}$
}

Received: 25 September 2019 / Accepted: 10 February 2020 / Published online: 20 February 2020

(c) Springer Nature Switzerland AG 2020

\begin{abstract}
Synthesis of Zinc Coneflower-Porous Starch composite for textile finishing was successfully synthesized. The Functional finish was developed to enhance the quality and durability of the textile fabrics against launderable issues, bacterial effects and tensile problems occurred in day to day usage of the textiles. Zinc oxide was prepared from ginger-mediated biogenic synthesis, extracted native starch was ball- milled for nanoporous starch micro particle synthesis. Composite was prepared from $\mathrm{ZnO}$ and starch for finishing on the fabric. UV-Vis spectroscopy shows the peak at $380 \mathrm{~nm}$ for zinc oxide, XRD patterns show the prominent peaks at $15^{\circ}, 17^{\circ}, 18^{\circ}, 23^{\circ}$ for starch and $32^{\circ}, 34^{\circ}, 36^{\circ}$ for $\mathrm{ZnO}$ indicated the presence of the materials. SEM shows the prepared composite with the morphology of $\mathrm{ZnO}$ coneflowers like structures and nanoporous starch microparticles and elemental composition of the materials confirmed by EDAX. The Developed finish on the fabric was investigated by SEM analysis, antibacterial studies, tear-strength test and fabric fastness to laundering test.

\section{Graphic Abstract}

Textile finish was developed from the composite prepared by the green synthesis of Zinc Coneflower and ball-milling method for the Porous starch. Developed finish was characterized by various methods.
\end{abstract}

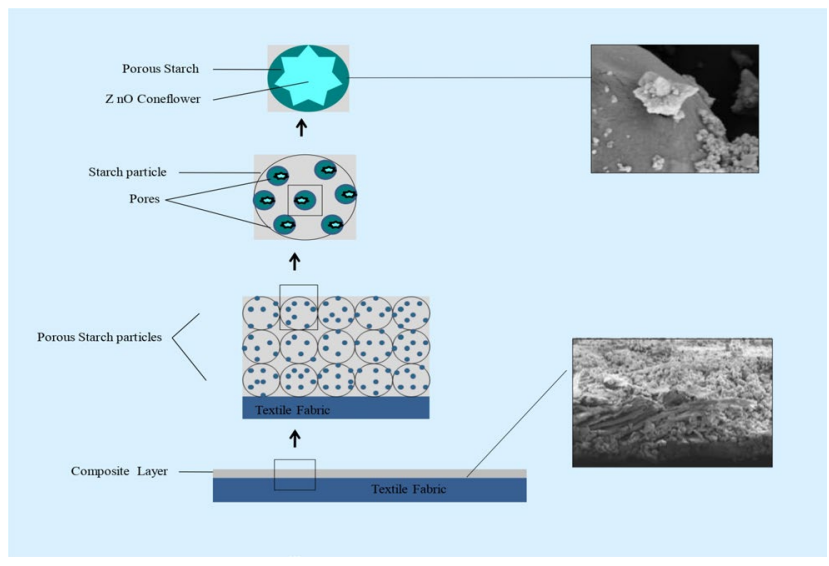

Keywords Zinc oxide coneflower · Porous starch · Ball milling · Biogenic synthesis · Textile finish

Electronic supplementary material The online version of this article (https://doi.org/10.1007/s42452-020-2229-y) contains supplementary material, which is available to authorized users.

Nitisha Mehrotra, nitiimehrotra2@gmail.com; $\bowtie$ Uma Venkatraman, umamcciyer@gmail.com |'Department of Nanoscience and Technology, Mount Carmel College, Bangalore 560052, India. ${ }^{2}$ Department of Chemistry, Mount Carmel College, Bangalore 560052, India. ${ }^{3}$ Present Address: CSIR-Indian Institute of Toxicology Research, Lucknow 226021, India. 


$\begin{array}{ll}\text { Abbreviations } \\ \mathrm{ZnO} & \text { Zinc Oxide } \\ \mathrm{TiO}_{2} & \text { Titanium oxide } \\ \mathrm{Al}_{2} \mathrm{O}_{3} & \text { Aluminium oxide } \\ \mathrm{MgO} & \text { Magnesium oxide } \\ \mathrm{CNTs} & \text { Carbon nanotubes } \\ \mathrm{PVDF} & \text { Polyvinylidene difluoride } \\ \mathrm{DMF} & \text { Dimethylformamide } \\ \mathrm{UV} & \text { Ultra violet } \\ \mathrm{XRD} & \text { X-ray diffraction } \\ \mathrm{SEM} & \text { Scanning electron microscope } \\ \text { EDAX } & \text { Energy dispersive X-ray analysis } \\ \text { AATCC } & \text { American Association of Textile Chemists and } \\ & \text { Colorists } \\ \mu l & \text { Micro litre } \\ \text { rpm } & \text { Rotations per minute }\end{array}$

\section{Introduction}

With the advent of Nano-tech textile industry has seen a multifarious innovations and momentous developments. These innovations have upgraded the legacy of textile technology. Considerable fabric treatments have been evolved which shows promising treatments to achieve enhanced fabric attributes, such as superior durability, softness, tear strength, abrasion resistance, durable-press and wrinkle- resistance, flexibility, washability. With the advent Nanotechnology in the textile industry made it multifunctional which can produce fibres with variable functions and applications such as UV protection, antiodor, anti-microbial, wrinkle-resistant and self-cleaning etc. [1]. Nanocomposites of mesosilicates, metal oxide nanoparticles, graphite nanofibers, CNTs, clay nanoparticles, metal oxide nanoparticles like $\mathrm{TiO}_{2}, \mathrm{Al}_{2} \mathrm{O}_{3}, \mathrm{ZnO}$ and $\mathrm{MgO}$ can be used for developing multifunctional textiles without affecting the inherent properties of textiles $[2,3]$. In Vigneshwaran et al. [4] reported Zinc oxide-soluble starch nanocomposites (nano-ZnO) synthesized using water as a solvent and soluble starch as a stabilizer is impregnated onto cotton fabrics to impart antibacterial and UV-protection functions. It was determined that nano-sized titanium dioxide and zinc oxide are more efficient at absorbing and scattering UV radiation than the conventional size, and are thus better to protect against UV rays. Metal oxides like $\mathrm{ZnO}$ as a UV-blocker are more stable when compared to organic UV-blocking agents. The nanostructure $\mathrm{ZnO}$ coatings are more air-permeable and efficient as UV-blockers compared to bulk $\mathrm{ZnO}$ and enhance the UV-blocking property due to the increased surface area and intense absorption in the UV region [4]. Research on the use of zinc oxide in polyester fibres has also been carried out at Poznan University of Technology and the Textile Institute in Lodz [5]. In Tamaki et al. [6] treated the potato starch which shows that surface becomes extremely rough and water absorption increased when treated for $10 \mathrm{~h}$. The 'Green synthesis' or 'biogenic synthesis shows better advancement over chemical and physical method as it is lesser toxic, cost-effective, environmentally friendly and also involve proteins as capping agents. The use of plants or their extracts, for the synthesis of nanoparticles, has been focused due to its simplicity, lower cost and also it involves proteins as capping or reducing agent $[7,8]$. In Raj and Jeyalakshmy [9] presented a study on the efficacy of Zingiber officinale for the biogenic synthesize of ZnO nanoparticles. Zinc oxide has diversifying properties which include catalysis, electrical conductivity, antibacterial activity, and cytotoxicity, high chemical stability, high electrochemical coupling coefficient, a broad range of radiation absorption and high photo stability, is a multifunctional material. Starch was chosen with $\mathrm{ZnO}$ for the composite as starch has efficient barrier properties while, $\mathrm{ZnO}$ acts as an anti-microbial agent which helps to increase the shelf-life duration and protects the material from oxidation, humidity and bacteria. Specialty finishes in the form of functional finishes plays a significant role in the value addition of technical textiles. Functional finishes on technical textiles are not just about the surface finish on the substrate but meeting with all functions in terms of performance and end-user requirements. Technical textiles today include textiles for automotive applications (car interiors, upholstery) medical textiles (wounds and dressings), geo-textiles (reinforcement of embankments), agro textiles (textile for crop protection) and protective clothing (heat and radiation protection for firefighter clothing and bulletproof vests) [10]. Functional finishes improve the performance of the textiles by inducing antibacterial properties, improving the tear strength and UV protective nature and colorfastness [11].

\section{Experimental}

\subsection{Materials and methods}

All the chemicals used in the research were of analytical grade and used without further purification. Chemicals were purchased from Merck Chemicals Ltd. and Sigma Aldrich, USA. Distilled water was used throughout the experiments; Corn and ginger were purchased from the local market of premium quality. Instruments like UV-Vis spectrophotometer (UV-1700, Pharma Spec-Shimadzu Corp.), SEM (ZEISS-Evo HD), Ball milling unit (VB ceramic Consultants), Centrifuge (39901-REMI). 


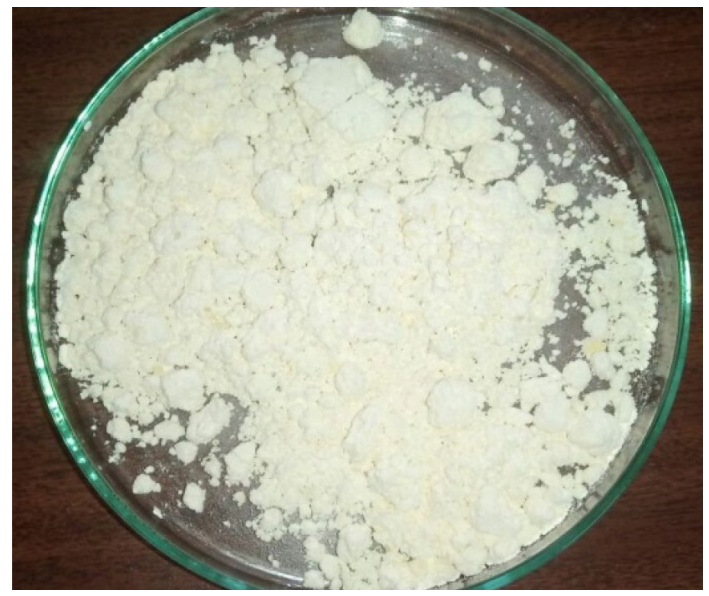

Fig. 1 Shows the extracted native starch powder from the maize by the old traditional method of starch extraction

\subsection{Extraction of native starch}

Native starch from the corn was extracted by using an old traditional method of starch extraction. Corn was purchased from the local market and refrigerated. Purchased corn was of export quality and globally available as Zea Mays. On the basis of literature survey it was found that amylose content in the native starch is around $70 \%$ while, amylopectin ranges from 20 to $30 \%$ [24]. Corn (100 g) was added in $300 \mathrm{~mL}$ distilled water and continuously stirred for $2 \mathrm{~h}$ at $50^{\circ} \mathrm{C}$ for softening and ground in the grinder using distilled water. The prepared paste was washed properly with water twice and left for some time to settled own. The mixture was filtered with the sieves and was poured into the Petri dishes for drying at $40^{\circ} \mathrm{C}$ for overnight. The dried powder in Fig. 1 was stored in the vacuum container for further use.

\subsection{Preparation of nano-porous starch by ball milling}

Native starch was used in the ball milling treatment for preparation of nano-porous starch. Native starch and balls were taken in the proportion of 1:10. The treatment was performed at $200 \mathrm{rpm}$ for $6 \mathrm{~h}$ on the room temperature in the ball milling unit instrument. After $6 \mathrm{~h}$ the starch was taken out from the unit ${ }^{1}$ and stored for the further experiments and characterization.

\footnotetext{
Figure 1(a) of electronic supplementary material.
}

\subsection{Green synthesis of zinc oxide coneflowers}

\subsubsection{Extraction of ginger extract}

Ginger was purchased from the local market, thoroughly cleaned and dried in the lab. Purchased ginger was of export quality and globally available as Zingiber officinale. The outer layer was peeled off and kept in a hot air oven for $2 \mathrm{~h} .5 \mathrm{~g}$ of ginger was taken and chopped finely into small pieces and mashed in mortar jar. Ginger pieces were boiled in $30 \mathrm{~mL}$ distilled water for 30 min for pure extracts; the boiled solution was filtered by using Whatman filter paper. The filtered extracted juice ${ }^{2}$ was stored properly in the refrigerator $\left(4^{\circ} \mathrm{C}\right)$ by covering with parafilm for further use.

\subsubsection{Ginger-mediated synthesis of zinc oxide coneflowers}

$50 \mathrm{~mL}$ of $(0.01 \mathrm{M})$ Zinc acetate dihydrate (Sigma Aldrich, USA) solution was prepared in $100 \mathrm{~mL}$ of distilled water, $800 \mu \mathrm{L}$ of the ginger extract was added to the zinc acetate solution and the $\mathrm{pH}$ was maintained by adding few drops of sodium hydroxide (Sigma Aldrich, USA). The concentration of ginger extract was fixed for $100 \mathrm{~mL}$ solution by the review and previous work carried on the biogenic synthesis using ginger $[7,15,26]$. The solution was continued to stir for $3 \mathrm{~h}$ and $30 \mathrm{~min}$ at room temperature, after stirring it was cleaned with distilled water by centrifuging it at $3000 \mathrm{rpm}$ for $5 \mathrm{~min}$. The supernatant was discarded and the centrifuged solution was kept for drying at $30^{\circ} \mathrm{C}$ overnight. After drying the obtained pale white powder was scraped out and stored properly at room temperature in the vacuum container. Presence of polyphenolic compounds, flavonoids and phytochemicals like oxalic acids, ascorbic acid and zingerone in the chemical composition of the ginger plays a crucial role in the recovery and mediates the formation of $\mathrm{ZnO}$ [26].

\subsection{Preparation of Zinc Coneflower-Porous Starch composite}

Different concentration of nanocomposites was prepared for different finishes. The concentration of ball-milled starch was $0.2 \mathrm{~g}$ for antibacterial finish, $0.25 \mathrm{~g}$ for tear strength and launderabilty, $0.1 \mathrm{~g}$ for colorfastness while the concentration of zinc oxide coneflowers was $0.2 \mathrm{~g}$ for antibacterial finish, $0.25 \mathrm{~g}$ for tear strength and launderabilty, $0.4 \mathrm{~g}$ for colorfastness by using (0.5\%) PVDF (Merck chemicals Itd.) with N, N-DMF (Sigma Aldrich, anhydrous 99.8\%) of total material as binder. Starch, ZnO, PVDF were

$\overline{2 \text { Figure } 1(b)}$ of electronic supplementary material. 

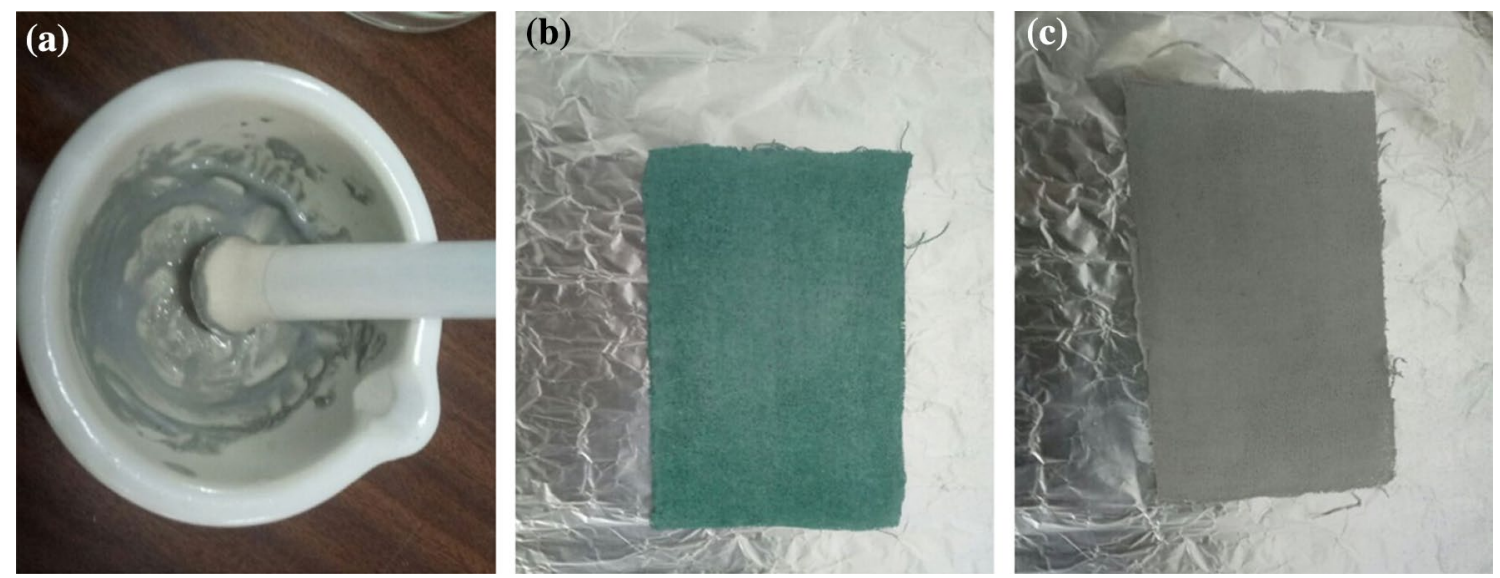

Fig. 2 a Shows the preparation of the composite material, $\mathbf{b}$ and $\mathbf{c}$ shows different fabrics coated with the composite material

Table 1 Shows fibrous composition of the fabric used

\begin{tabular}{ll}
\hline Component & Amount (dry basis) (\%) \\
\hline Cellulose & 94 \\
Protein & 1.3 \\
Pectin substances & 0.9 \\
Oil, fat and wax & 0.6 \\
Ash & 1.2 \\
Malic acid, citric acid and & 0.8 \\
$\quad$ other acids & \\
Total sugar & 0.3 \\
Pigment & Traces \\
Others & 0.9 \\
\hline
\end{tabular}

mixed in the mortar jar properly by using DMF as composite prepared for fabrics used in the different finishing tests shows in Fig. 2. ${ }^{3}$ The fabrics were coated using dip coating method by immersing the fabric in the prepared composite solution for 4-5 times and dried at room temperature to perform the several tests needed. The fibrous composition of the fabric used for the experimental purposes is shown in Table 1. The surface density of the fabric was around of $1.52 \mathrm{~g} / \mathrm{cm}^{3}$ along with the $9000-15,000$ of degree of polymerization $[27,28]$.

\section{Result and discussion}

Zinc Coneflower-Porous Starch composite for Finishing on Fabrics was prepared by using ball milling and green synthesis method was investigated by different characterization techniques. Optical studies were carried out

\footnotetext{
3 (a) Represents the composite preparation.
}

Table 2 UV-Vis data of $\mathrm{ZnO}$ coneflowers

\begin{tabular}{ll}
\hline Wavelength $(\mathrm{nm})$ & Absorption (\%) \\
\hline 600 & 0.4407 \\
580 & 0.453 \\
560 & 0.4677 \\
540 & 0.4846 \\
520 & 0.5033 \\
500 & 0.5233 \\
480 & 0.5455 \\
460 & 0.5715 \\
440 & 0.6034 \\
420 & 0.6412 \\
400 & 0.6921 \\
380 & 0.7755 \\
360 & 0.7552 \\
340 & 0.7524 \\
320 & 0.7515 \\
300 & 0.7729 \\
280 & 0.797 \\
260 & 0.8002 \\
240 & 0.8101 \\
220 & 0.9271 \\
\hline
\end{tabular}

by using UV-Vis spectroscopy, the crystallographic information was investigated by X-ray diffraction (XRD), and the morphology of the materials and fabric finishes were characterized by the Scanning electron microscope. The functionality of the finishes was tested by antibacterial activity, tensile strength, UV resistant test and color fastness with launderabilty for the developed finish over the fabrics. The purpose of the composite treated textile is to develop functional finish on the fabrics for varied applications in chemical protective textiles and clothing, medical textiles, protection from radiation and smart textiles.

\section{SN Applied Sciences}




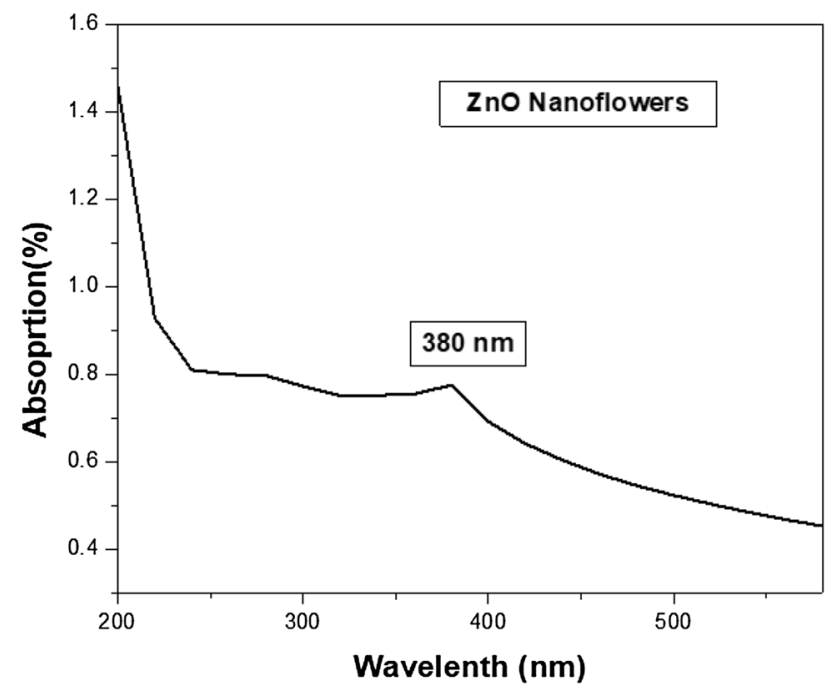

Fig. 3 Shows the UV-Vis spectra for zinc oxide

\subsection{UV-visible absorption spectrum}

The optical properties of the sample were examined by UV-1700 Pharma spec (UV-Vis spectrophotometer). Optical absorption measurement was carried out on Zinc oxide material which was prepared from the ginger-mediated synthesis. The optical absorption has been carried out in the wavelength range of 220-600 nm shown in Table 2. The absorption peak was obtained at $380 \mathrm{~nm}$ for $\mathrm{ZnO}$ coneflowers [12]. Figure 3 shows the UV Vis spectra ${ }^{4}$ of the prepared Zinc Oxide Coneflowers.

\subsection{X-ray diffraction}

The XRD spectrum of the native starch and ball milled starch is shown in Figs. 4 and 5. Native starch shows the characteristic peak at $2 \theta=15.07,17.14,18,23.02$, while ball milled starch shows the peak at $2 \theta=15.15,17.20,18.02$, 23.06. These characteristic peaks represent A-type crystalline arrangement. The crystallinity index of native starch and ball milled starch was analyzed using X-Ray diffraction. The relative crystallinity index $(\mathrm{Cl})$ of starch was calculated using the Segal [13], which is, $\mathrm{Cl}(\%)=([(\mathrm{I} 002-\mathrm{I}$ am $)] / \mathrm{I}$ $002)^{*} 100$, in which 1002 is the maximum intensity of the 002 peaks at approximately $2 \theta=18^{\circ}$ and $\mathrm{I}$ am representing the intensity corresponding to the peak at $2 \theta=21^{\circ}-22^{\circ}$. The crystallinity index of the native starch was found at $34.97 \%$, while for the ball milled treated starch is at $33.2 \%$. Starch is amorphous and semi-crystalline in nature.

\footnotetext{
${ }^{4}$ Table 2 represents the UV Vis Spectra data recordings.
}

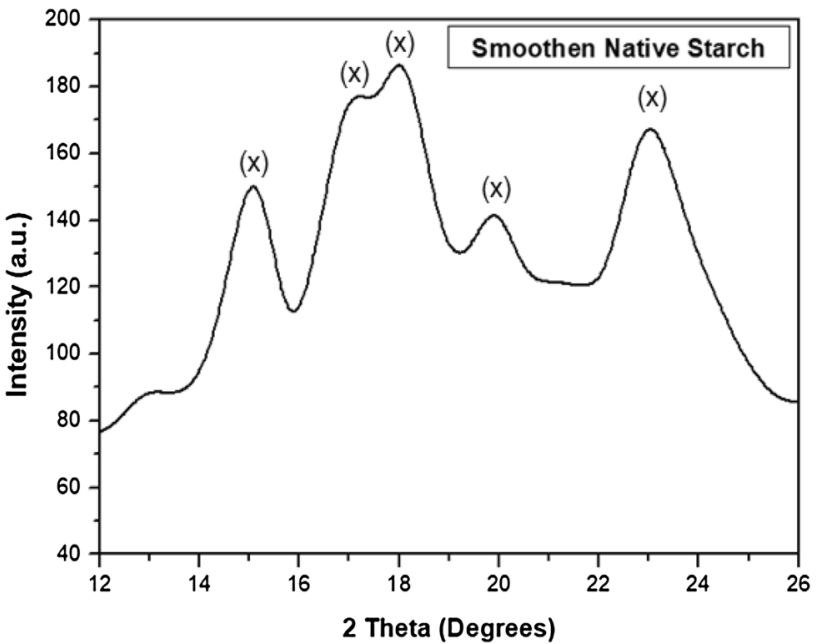

Fig. 4 Shows the XRD of native starch where, $X$ indicates the formation of starch with a characteristic peak at $2 \theta=15.07,17.14,18$, 23.02

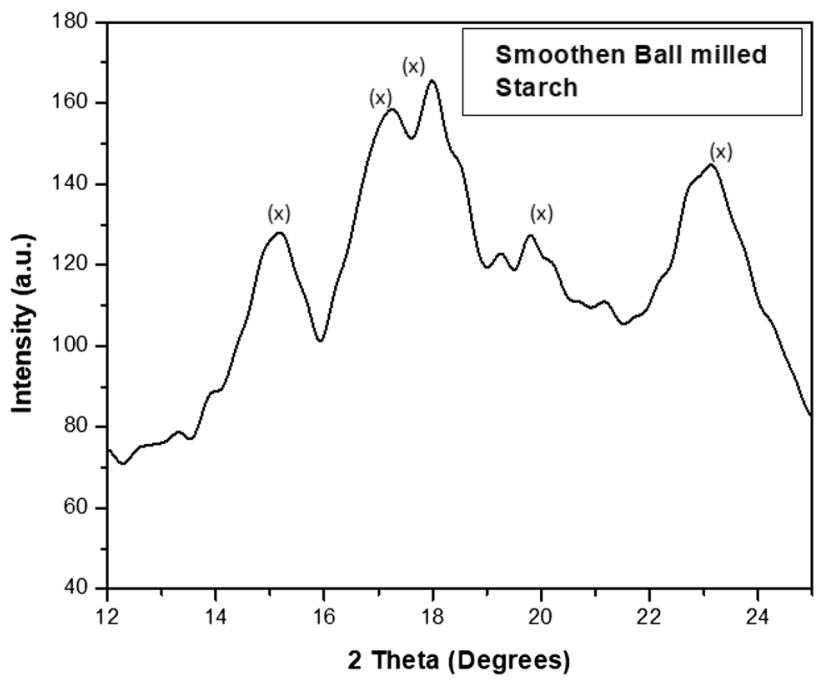

Fig. 5 Shows the XRD of ball milled starch where, $X$ indicates the formation of starch with a characteristic peak at $2 \theta=15.15,17.20$, $18.02,23.06$

Crystallinity represents the amylopectin regions while amorphous regions were represented by the amylose and $\mathrm{Cl}$ for starch is between 30 and 50\% [6]. Amylose content was found to be increased by $0.3-0.5 \%$ on ball milling treatment. Ball milling results in the change of crystallinity depending upon the temperature and duration of treatment causing mechanical and heat effects of dry milling $[6,25]$. From the carried literature survey it was found that molecular weight of starch slightly decreases by $4-5 \%$ on treatment resulting in the decrease of density of starch due to the degradation and change in the physical properties caused by the ball milling treatment $[6,13,24,25]$. 


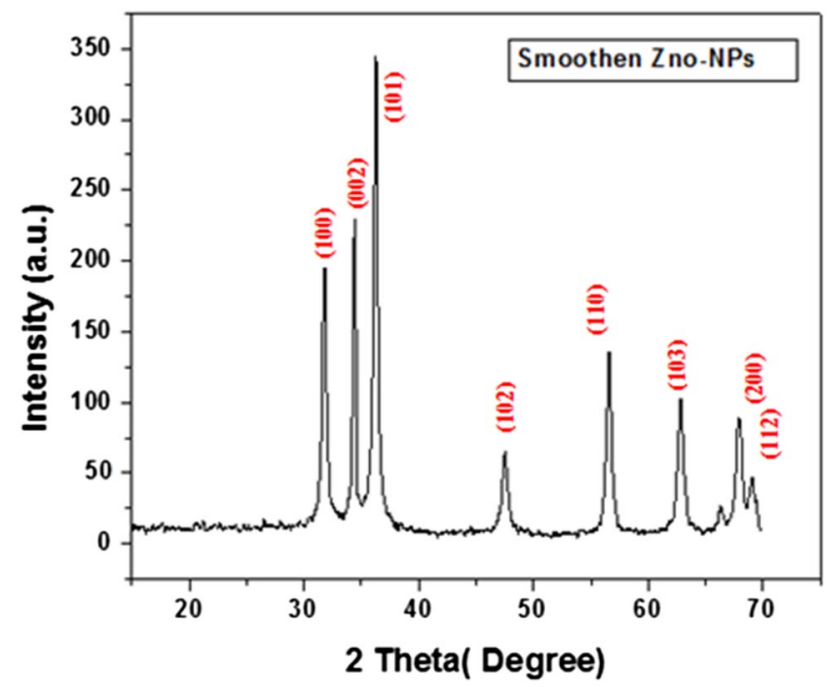

Fig. $6 \mathrm{XRD}$ of $\mathrm{ZnO}$ coneflowers. The major peaks were obtained at $36^{\circ}, 34^{\circ}, 32^{\circ}$ for the hkl (101), (002), (100) planes

Small change in the $\mathrm{Cl}$ and the XRD patterns of the native starch and ball milled starch contributes to it.

The XRD Patterns of $\mathrm{ZnO}$ shows in Fig. 6. The Major peaks were obtained at $36^{\circ}, 34^{\circ}, 32^{\circ}$ for the $\mathrm{hkl}$ (101), (002), (100) planes confirms the formation of $\mathrm{ZnO}$ as a hexagonal type structure. The average crystallite size $(D)$ is obtained at $23.24 \mathrm{~nm}$, Lattice Distance (d)is $2.81 \AA$ while the lattice parameters a and c are $3.25 \AA$ and $5.63 \AA$ by using formula- $a_{(100)}=Z / \sqrt{ } 3 \operatorname{Sin} \Theta, c_{(100)}=Z / \operatorname{Sin} \Theta, d=Z / 2 \operatorname{Sin} \Theta[14]$.

\subsection{Scanning electron microscope}

The morphology of ball-milled starch was observed in Fig. 7. For different magnifications, starch microparticles with nanopores on the surface can be seen. Ball milling treatment results in the surface crevices and rough starch granules, shape of the starch granules changes into oval or flat pattern on treatment $[6,24,25]$. Pores from the range of 131-367 nm were found all over the surface of the starch particles. Porosity helps in the composite formation as other material $\mathrm{ZnO}$ can be easily filled into these pores and enhances the composite features which may be beneficial for the finishing on the fabrics. The porous starch was obtained because the native starch was ball-milled for longer period which generates the heat in the milling unit leads to the change in surface morphology of the starch.

The morphology of the $\mathrm{ZnO}$ coneflowers prepared from the ginger mediated green synthesis can be observed in Fig. 8. It shows that nano-cones with coneflowers are obtained and the polydispersity ranges from 55 to $133 \mathrm{~nm}$. Ginger extract used in the synthesis process acts as the reducing agent for the $\mathrm{ZnO}$, the concentration variation of the reducing agents have a direct impact on the change in the morphology of material leads to the formation of nano-cones and coneflowers [15]. The morphology of the Zinc Coneflower-Porous Starch composite can be observed in Fig. 9. It clearly shows that the pores found on the starch surface were filled with the prepared $\mathrm{ZnO}$ material, also we can observe that a portion $\mathrm{ZnO}$ coneflowers filled the starch pores and rest of the lower surface is facing outward, some of the $\mathrm{ZnO}$ is present on the surface of the starch. Also, $\mathrm{ZnO}$ flowers of $1.5 \mu \mathrm{m}$ can be found on the surface of ball-milled starch material. Starch and $\mathrm{ZnO}$ were chosen for the composite because Starch can increase the shelf life of the prepared composite as starch has a barrier property which protects the material from deteriorations such as oxidation, humidity, and bacteria but it has low barrier properties to oxygen [16]. The morphology of
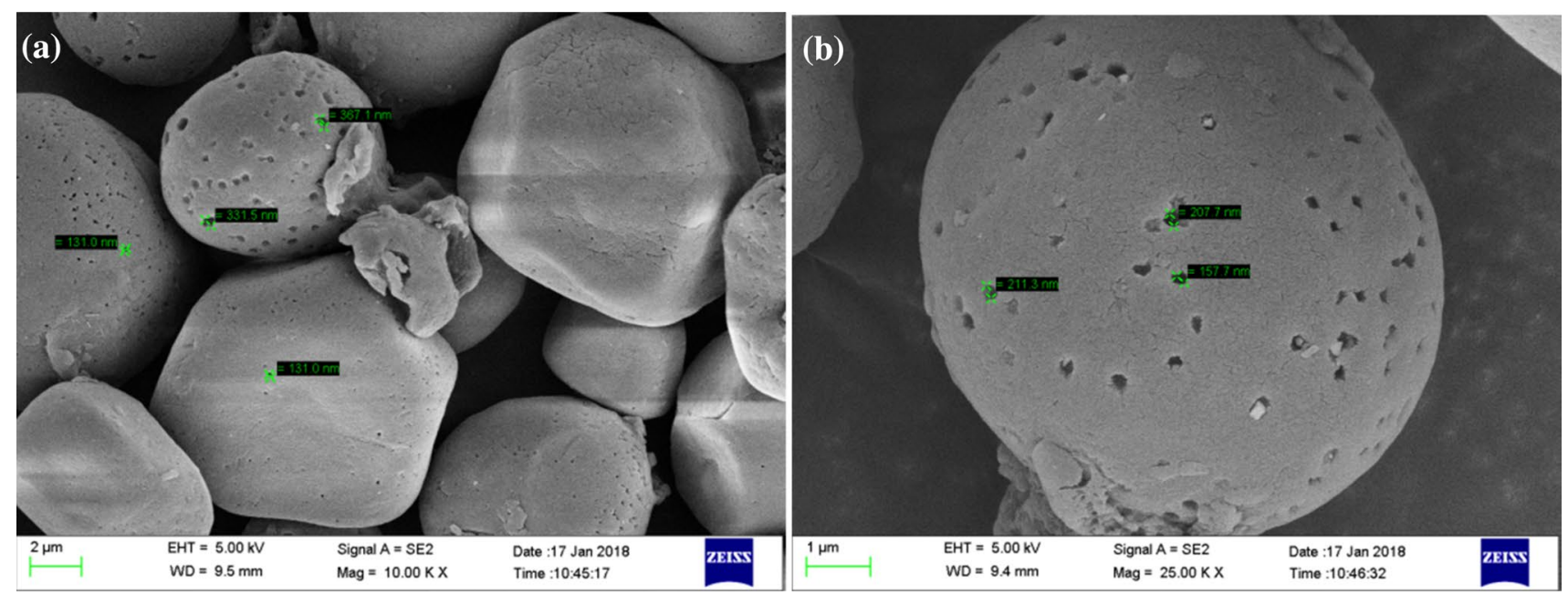

Fig. 7 Shows the SEM images of the ball-milled porous starch $(\mathbf{a}, \mathbf{b})$ at different magnifications 

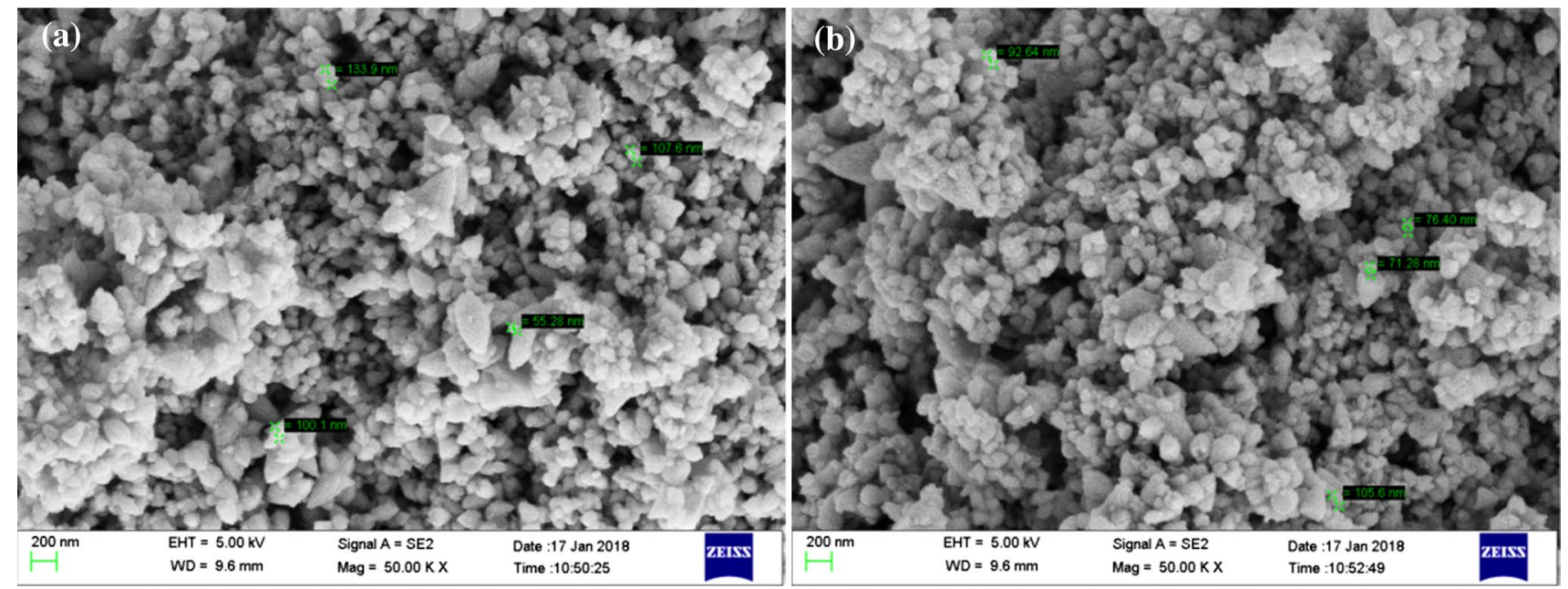

Fig. 8 Shows the SEM images of $\mathrm{ZnO}$ coneflowers $(\mathbf{a}, \mathbf{b})$
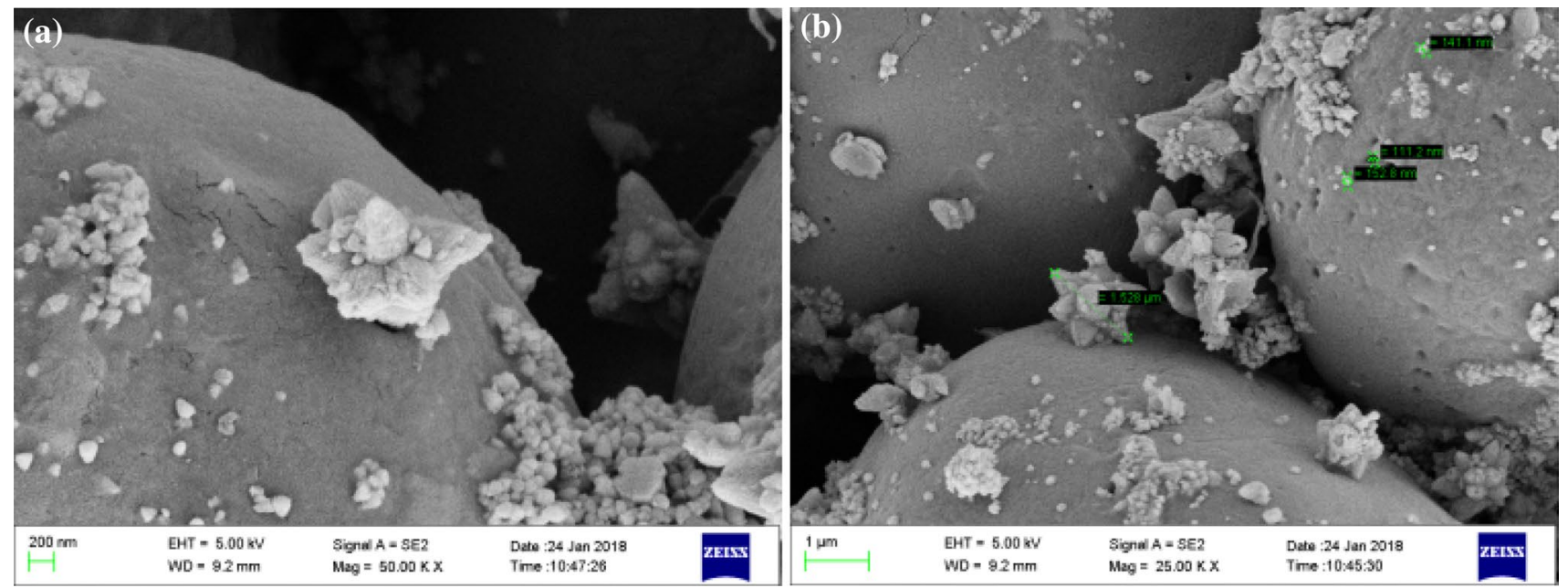

Fig. 9 Shows the SEM images of the $\mathrm{ZnO}$ coneflower-porous starch composite at different magnifications in $\mathbf{a}, \mathbf{b}$

the Composite coated fabric can be observed in Fig. 10 . It clearly shows that the fabric was uniformly coated with the Coneflower-porous starch. At different magnifications composite coats the warp and the weft yarns of the fabric, the coating material was embedded the protruding fibres on the yarns of the fabric. Composite behaves as the sizing material which results in the film-forming property.

\subsection{Energy dispersive X-ray analysis (EDAX)}

The EDAX analysis of ball-milled starch in Fig. $11^{5}$ reveals that starch only contains carbon (C) and oxygen (O) as a

\footnotetext{
5 Table 3 shows the EDAX of the ball-milled porous starch.
}

part of the composition and also it reveals the presence of small amount of gold ( $\mathrm{Au}$ ) as an impurity which comes from the gold coating done during the sample preparation for SEM imaging.

The EDAX analysis shows the elemental composition of the prepared zinc oxide material from the ginger mediated green synthesis in Fig. $12 .{ }^{6}$ Results show that the pure zinc oxide material was formed as it didn't confirm the presence of any kind of impurity.

The EDAX analysis shows the elemental composition of the $\mathrm{ZnO}$ impregnated starch composite prepared from the ball-milled starch and zinc oxide prepared from the ginger

\footnotetext{
6 Table 4 shows the EDAX of the $\mathrm{ZnO}$ coneflowers.
} 

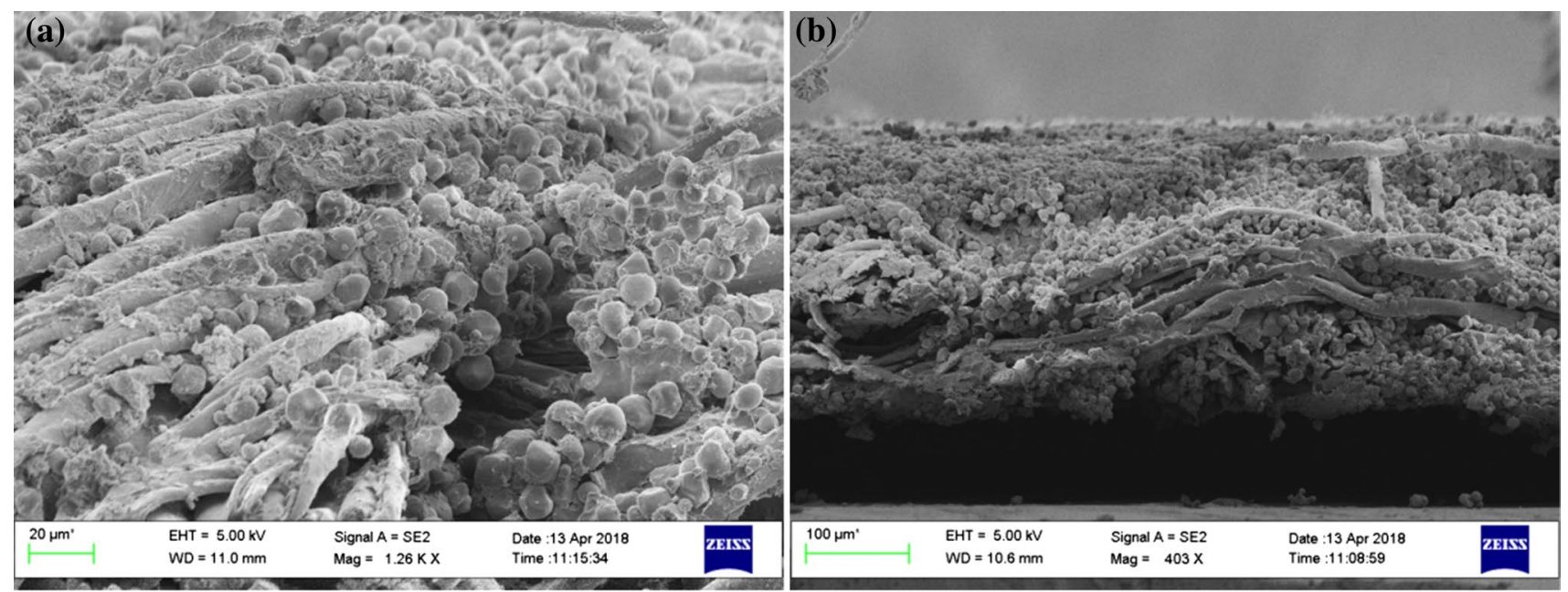

Fig. 10 Shows the SEM images of the Composite coated fabric at different magnification in $\mathbf{a}, \mathbf{b}$

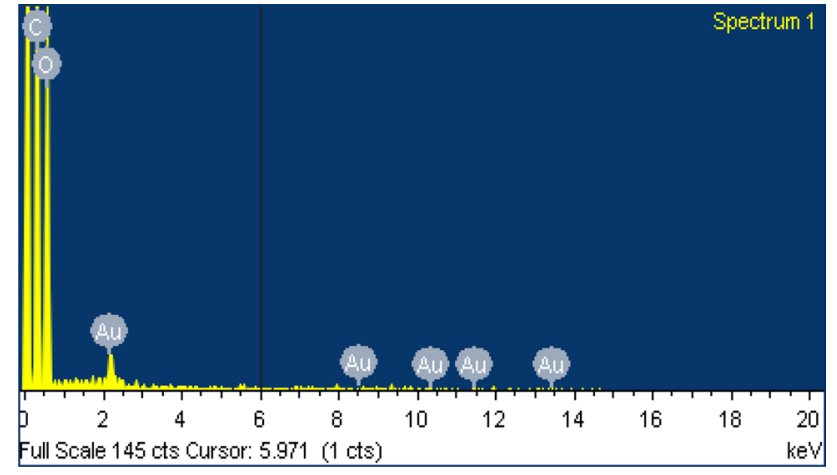

Fig. 11 Shows the spectrum of ball-milled porous starch by EDAX analysis confirming the presence of Carbon, Oxygen and Gold

Table 3 EDAX of ball-milled porous starch

\begin{tabular}{lll}
\hline Element & Weight\% & Atomic\% \\
\hline C K & 45.11 & 54.45 \\
O K & 49.85 & 45.18 \\
Au M & 5.03 & 0.37 \\
Total & 100 & 100 \\
\hline
\end{tabular}

mediated synthesis in Fig. 13. ${ }^{7}$ We can easily analyze from the image that prepared composite contains only carbon $(\mathrm{C})$, oxygen $(\mathrm{O})$, zinc $(\mathrm{Zn})$ and gold $(\mathrm{Au})$ is present as an impurity which comes from the gold coating done during the sample preparation for SEM imaging.

\footnotetext{
7 Table 5 shows the EDAX of the $\mathrm{ZnO}$ coneflower- porous starch composite.
}

\section{SN Applied Sciences}

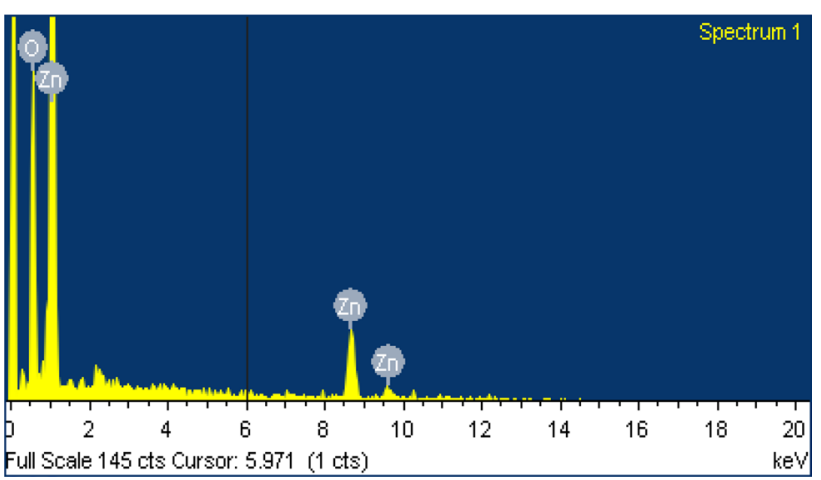

Fig. 12 Shows the spectrum of $\mathrm{ZnO}$ coneflower by EDAX analysis confirming the presence of Zinc, Oxygen and Gold

Table 4 EDAX of Zinc oxide coneflowers

\begin{tabular}{lll}
\hline Element & Weight\% & Atomic\% \\
\hline O K & 29.40 & 62.98 \\
Zn K & 70.60 & 37.02 \\
Total & 100 & 100 \\
\hline
\end{tabular}

\subsection{Antibacterial studies}

Figure 14 shows the antibacterial activity studies of grampositive and negative bacteria, where $A$ is composite, $B$ is $\mathrm{ZnO}, \mathrm{C}$ is starch, $\mathrm{D}$ is control and $\mathrm{E}$ is acid-treated starch for Staphylococcus aureus and Serratia marcescens respectively but for $E$. coli A is composite, B is control, C is starch, D is 


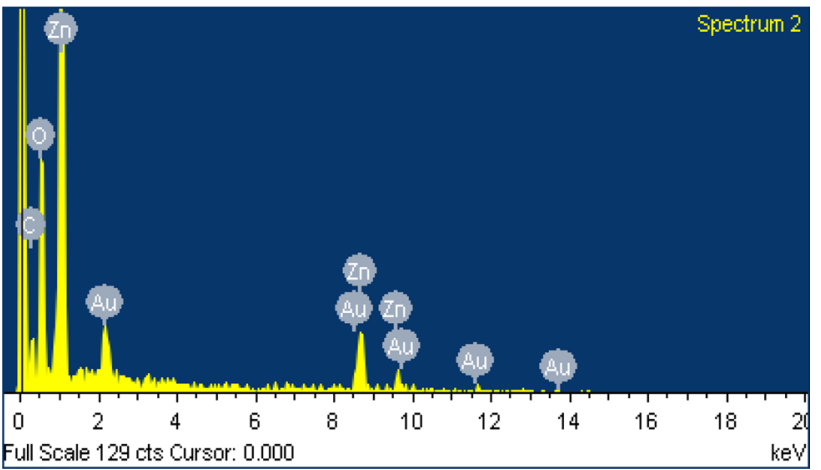

Fig. 13 Shows the spectrum of Zinc Coneflower-Porous Starch composite by EDAX analysis showing the presence of Carbon, Oxygen, Zinc and Gold

Table 5 EDAX of $\mathrm{ZnO}$ coneflower and porous starch composite

\begin{tabular}{lll}
\hline Element & Weight\% & Atomic\% \\
\hline C K & 15.03 & 34.26 \\
O K & 25.31 & 43.32 \\
Zn K & 50.43 & 21.13 \\
Au K & 9.24 & 1.29 \\
Total & 100 & 100 \\
\hline
\end{tabular}

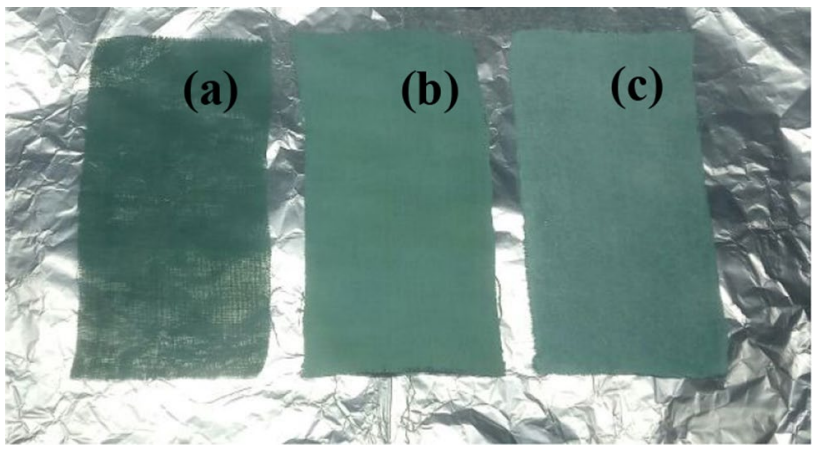

Fig. 15 Shows the sample used for the tear strength test, a noncoated sample, b composite coated sample, $\mathbf{c}$ starch coated sample

$\mathrm{ZnO}$ and $\mathrm{E}$ is acid-treated starch and the control used here is negative control. Zinc Oxide has proved to be a powerful antibacterial agent. ZnO nanoparticles show greater antibacterial activity than microparticles. $\mathrm{ZnO}$ particles have a bactericidal effect against $E$. coli, S. aureus and for S. marcescens, but the exact mechanism of antibacterial activity has not been identified [17] (Fig. 14).

The results of antibacterial studies of starch crystals, zinc oxide coneflowers and composite are summarized
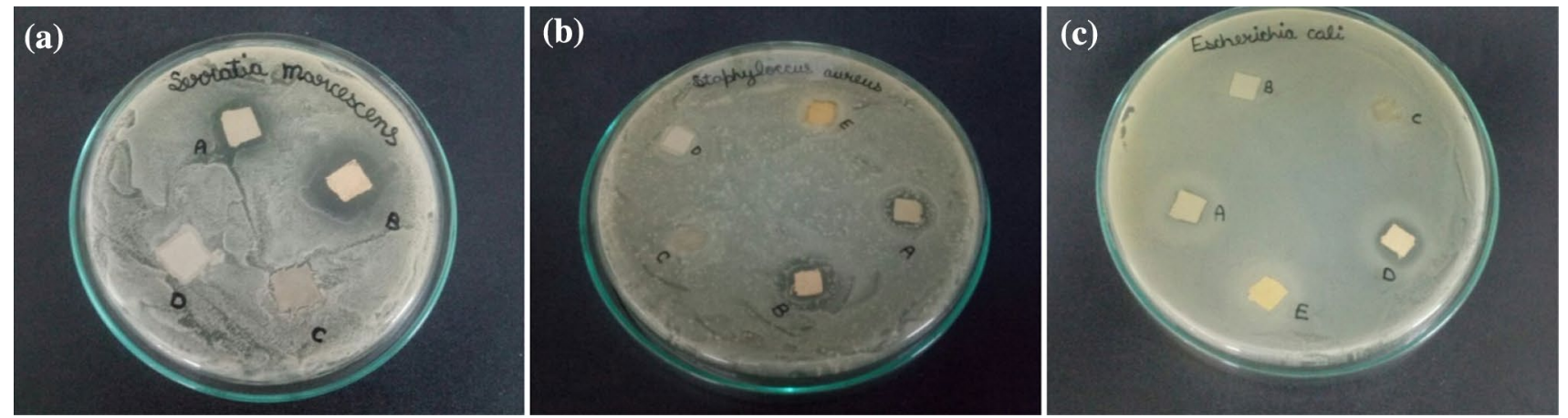

Fig. 14 Shows the antibacterial studies, a shows the effect against E. coli. b Shows against Serratia marcescens, c shows effect against $S$. aureus

Table 6 Diameter of the Inhibition Zones of Starch, $\mathrm{ZnO}$ and Composite material

\begin{tabular}{llll}
\hline Disks & E. coli & Staphylococcus aureus & $\begin{array}{l}\text { Serratia Marces- } \\
\text { cens }\end{array}$ \\
\hline Composite & $11 \mathrm{~mm}$ & $11 \mathrm{~mm}$ & $15 \mathrm{~mm}$ \\
Zinc oxide & $16 \mathrm{~mm}$ & $12 \mathrm{~mm}$ & $19.4 \mathrm{~mm}$ \\
$\begin{array}{l}\text { Ball milled starch } \\
\begin{array}{l}\text { Acid hydrolysed + ultrasoni- } \\
\text { cated starch }\end{array}\end{array}$ & 0 & 0 & 0 \\
\hline
\end{tabular}


in Table $6 .{ }^{8}$ The initial diameter of all the samples was fixed at $10 \mathrm{~mm}$. The diameters of the clear inhibition zones were used to determining the antibacterial activity. According to the results obtained, starch crystals prepared from both ball milling treatment as well as acid hydrolyzed starch shows absence of clear inhibition zone which means that there is no antibacterial activity. Acid hydrolyzed starch was also prepared by using cold acid hydrolysis and ultrasonication method [18, 21]. Zinc oxide coneflowers shows the inhibition zones of diameter $16 \mathrm{~mm}$ for E. coli, $12 \mathrm{~mm}$ for S. aureus and $19.4 \mathrm{~mm}$ for S. marcescens. It was shown that prepared composite exhibit inhibition zone of diameter $11 \mathrm{~mm}$ for E. coli, $11 \mathrm{~mm}$ for S. aureus and $15 \mathrm{~mm}$ for S. marcescens respectively.

\subsection{Tear strength test}

Tear strength test was performed for the fabrics coated with starch and composite and for the bare sample shown in Fig. 15 [19]. Samples prepared are of diameter $8 \mathrm{~cm} \times 12 \mathrm{~cm}$ to test the tear strength of the fabrics. Test results show that for the bare sample which is non coated fabric tear load were $960 \mathrm{~g}$ which means we had to apply $960 \mathrm{~g}$ of load to tear the fabric. For starch coated sample the tearing load was decreased to $768 \mathrm{~g}$ and for composite coated sample applied tear load was $1152 \mathrm{~g}$. From the test results, we can conclude that for the starch coated fabric tear strength gets reduced by $192 \mathrm{~g}$ while for the composite coated fabric it gets enhanced by $192 \mathrm{~g}$. Composite coated fabric shows good tear strength results than compared to the non coated fabric and starch coated fabric because the starch coated fabrics were stiff enough to tear easily while the composite coated fabrics were bit flexible comparatively to none coated and starch coated fabrics.

\subsection{UV-Resistant test}

UV resistant test helps to analyze the UV resistant nature of the fabrics coated with Starch, Zinc oxide material and non coated fabric. Figure 16(1) shows the fabrics under the exposure to the white light, while Fig. 16(2) shows the fabric under the exposure to the UV light. The above images clearly show that all three samples of fabric shows the different UV resistant nature by the intensity of light reflected by the fabrics. Sample (a) of the above images is the non coated sample which shows very high-intensity light reflection when exposed under UV light compared with

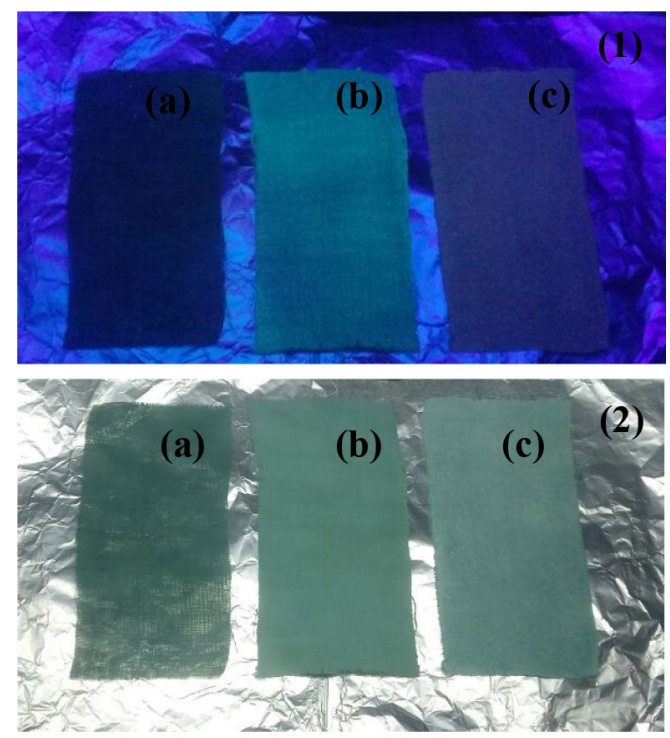

Fig. 16 Shows the coated and non coated fabrics under the UV light exposure (1) versus visible light (2), where a non-coated sample, b composite coated sample, c starch coated sample

Table 7 Shows the test results for the rating of colour change and staining for the coated fabrics

\begin{tabular}{lll}
\hline Samples & $\begin{array}{l}\text { Rating for colour } \\
\text { change }\end{array}$ & Rating for staining \\
\hline Bare (non coated) & 2 & $3 / 4$ \\
Starch coated & 3 & 4 \\
Composite coated & $3 / 4$ & $4 / 5$ \\
\hline
\end{tabular}

the Visible light exposure, similarly sample (b) is the composite coated sample which shows very low light intensity reflection under UV light compared with the Visible light exposure and sample (c) is the starch coated sample which shows the high-intensity light reflection under UV light compared with the Visible light exposure. The UV-blocking property of a fabric is enhanced when a dye, pigment, delustrant, or UV absorber finish is present that absorbs UV radiation and blocks its transmission through the fabric to the skin [20], the similar effect can be seen in sample (b) of Fig. 16. ZnO acts as a UV-blocker are more stable when compared to organic UV-blocking agents. Hence, the nano form $\mathrm{ZnO}$ composite with starch will enhance the UV-blocking property due to the increased surface area and intense absorption in the UV region [22].

\footnotetext{
8 Table 6 shows the Diameter of the Inhibition Zones of Starch, $\mathrm{ZnO}$ and Composite material.
} 


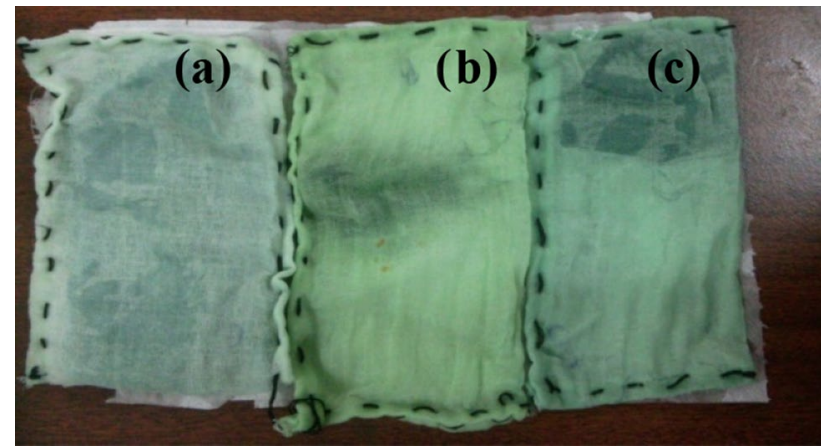

Fig. 17 Shows the colorfastness change of the fabrics, where a non-coated sample, b starch coated sample, c composite coated sample

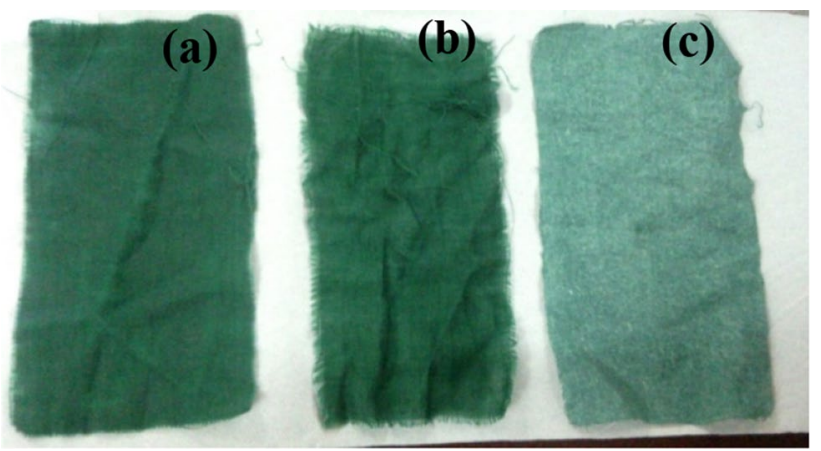

Fig. 18 Shows the Laundered fabrics, where a non coated sample, b starch coated sample, c composite coated samples

\subsection{Fabric fastness to laundering}

In this method, two tests were performed including color fastness and launderabilty test by using AATCC Test Method 61 [23]. The tests were performed at $45^{\circ} \mathrm{C}$ for $45 \mathrm{~min}$, weight of the samples were checked before the tests and were found to be at $1.52 \mathrm{~g}$ for starch coated fabric, $1.1 \mathrm{~g}$ for bare sample and $1.46 \mathrm{~g}$ for composite coated fabrics, the addition of the non-ionic and non-pigmented soap depend upon the above-mentioned weight to perform the test in the ratio of 1:40. Table $7^{9}$ represents the test results depending upon the values which are:

- 5-for excellent

- 4-for very good

- 3-for good/average

- 2-for poor

- 1-for very poor

\footnotetext{
9 Shows the test results for the rating of colour change and staining for the coated fabrics.
}

From the Figs. 17 and 18 we can analyzed that on treated with soap the fabrics show the color change and staining mentioned in Table 7 and also the fabrics on treated at $45^{\circ} \mathrm{C}$ for $45 \mathrm{~min}$ with soap in the launderometer shows the loss of material coated on the fabric by $40 \%$ for starch coated fabric and $11.9 \%$ for composite coated fabrics compared to non laundered sample (Table 7).

\section{Conclusion}

Zinc Coneflower-Porous Starch composite for functional finishing on fabrics was successfully synthesized by using ball-milled starch crystals and zinc oxide coneflowers prepared from the ginger mediated green synthesis. Materials were characterized using UV-Vis absorption spectroscopy, $X R D, S E M, E D A X$ analysis. SEM images of the prepared composite show that pore's present on the starch surface was filled with the prepared $\mathrm{ZnO}$ material and the material shows the uniform coating on the yarns of the fabric. SEM analysis of the composite coated fabrics shows the uniform coating on the warp and weft threads of the fabric and the antibacterial study, tear-strength tests and launderabilty shows the improved results in the composite coated fabrics comparatively. From the results obtained by the tests performed on the fabric we can conclude that the prepared composite shows the effective results as it shows the good antibacterial activity against gram-positive and negative bacteria, good UV resistant nature, improved tear strength and good color fastness and launderabilty ratings compared to non coated fabrics and the starch coated fabrics.

Acknowledgements The authors would like to thank Dr. Sister Arpana Principal of Mount Carmel College for allowing us to access the major research lab for experimentation, B. Archana Associate professor, Department of fashion and apparel designing for providing the platform to carry out the finishing tests.

Author's contribution NM completed the paperwork as her master's thesis project. U.V guided the team to work in the direction, C.V and N.S.K supervised the work and P.N helped in the data analysis and suggestion of ball-milling method.

\section{Compliance with ethical standards}

Conflict of interest The authors declare that they have no conflict of interest.

\section{References}

1. Wang CC, Chen CC (2005) Physical properties of crosslinked cellulose catalyzed with nano titanium dioxide. J Appl Polym Sci 97(6):2450-2456 
2. Coyle S, Wu Y, Lau KT, De Rossi D, Wallace G, Diamond D (2007) Smart nano textiles: a review of materials and applications. MRS Bull 32(5):434-442

3. Wang R, Xin JH, Tao XM, Daoud WA (2004) ZnO nanorods grown on cotton fabrics at low temperature. Chem Phys Lett 398(1-3):250-255

4. Vigneshwaran $\mathrm{N}$, Kumar S, Kathe AA, Varadarajan PV, Prasad V (2006) Functional finishing of cotton fabrics using zinc oxidesoluble starch nanocomposites. Nanotechnology 17(20):5087

5. Chandra JH, Raj LA, Namasivayam SKR, Bharani RA (2013) Improved pesticidal activity of fungal metabolite from Nomureaerileyi with chitosan nanoparticles. In: 2013 international conference on advanced nanomaterials and emerging engineering technologies (ICANMEET). IEEE, pp 387-390

6. Tamaki S, Hisamatsu M, Teranishi K, Adachi T, Yamada T (1998) Structural change of maize starch granules by ball-mill treatment. Starch-Stärke 50(8):342-348

7. Vidya C, Hiremath S, Chandraprabha MN, Antonyraj ML, Gopal IV, Jain A, Bansal K (2013) Green synthesis of ZnO nanoparticles by Calotropis gigantea. Int J Curr Eng Technol 1:118-120

8. Nagarajan S, Kuppusamy KA (2013) Extracellular synthesis of zinc oxide nanoparticle using seaweeds of the Gulf of Mannar, India. J Nanobiotechnol 11(1):39

9. Raj LFA, Jayalakshmy E (2015) Biosynthesis and characterization of zinc oxide nanoparticles using root extract of Zingiber officinale. Orient J Chem 31(1):51-56

10. Sivaramakrishnan CN (2015) Functional finishes on technical textiles. Int J Text Eng Process 1(3):1-4

11. Functional finishes for Cotton products: Technical Bulletin. Cotton Incorporated: 6399 Weston Parkway, Cary, North Carolina, 27513. https://www.cottoninc.com/wp-content/uploa ds/2017/12/ISP-1012-Functional-Finishes-For-Cotton-Produ cts.pdf

12. Zak AK, Razali R, Majid WA, Darroudi M (2011) Synthesis and characterization of narrow size distribution of zinc oxide nanoparticles. Int J Nanomed 6:1399

13. Segal LGJMA, Creely JJ, Martin AE Jr, Conrad CM (1959) An empirical method for estimating the degree of crystallinity of native cellulose using the X-ray diffractometer. Text Res J 29(10):786-794

14. Qian L, Hinestroza JP (2004) Application of nanotechnology for high-performance textiles. J Text Appar Technol Manag 4(1):1-7

15. Kim HS, Seo YS, Kim K, Han JW, Park Y, Cho S (2016) Concentration effect of reducing agents on green synthesis of gold nanoparticles: size, morphology, and growth mechanism. Nanoscale Res Lett 11(1):230

16. Ortega-Toro R, Collazo-Bigliardi S, Talens Oliag P, Chiralt Boix M (2016) Thermoplastic starch: improving their barrier properties. Agronomía Colombiana 34(1):S73-S75

17. Rezende CP, Da Silva JB, Mohallem NDS (2009) Influence of drying on the characteristics of zinc oxide nanoparticles. Braz J Phys 39(1A):248-251

18. Kim HY, Park DJ, Kim JY, Lim ST (2013) Preparation of crystalline starch nanoparticles using cold acid hydrolysis and ultrasonication. Carbohyd Polym 98(1):295-301

19. AATCC Test Methods, Technical Manual and Standard. https:// www.aatcc.org/test/methods/

20. Dong WG, Huang G (2002) Research on properties of nano polypropylene/ $\mathrm{TiO}_{2}$ composite fibre. J Text Res 23:22-23

21. Putaux JL, Molina-Boisseau S, Momaur T, Dufresne A (2003) Platelet nanocrystals resulting from the disruption of waxy maize starch granules by acid hydrolysis. Biomacromol 4(5):1198-1202

22. Gulrajania ML, Gupta D (2011) Emerging techniques for functional finishing of textiles. Indian J Fibre Text Res 36:388-397

23. Colorfastness to Laundering, AATCC Test Method 61, Manufacturing Solutions Center: 301 Conover Station, SE. http://www. manufacturingsolutionscenter.org/colorfastness-to-laundering -testing.html

24. Shi L, Cheng F, Zhu PX, Lin Y (2015) Physicochemical changes of maize starch treated by ball milling with limited water content. Starch-Stärke 67(9-10):772-779

25. Liu TY, Ma Y, Yu SF, Shi J, Xue S (2011) The effect of ball milling treatment on structure and porosity of maize starch granule. Innov Food Sci Emerg Technol 12(4):586-593

26. Singh RP, Magesh S, Rakkiyappan C (2011) Ginger (Zingiber officinale) root extract: a source of silver nanoparticles and their application. Int J Bio-Eng Sci Technol 2(3):75-80

27. Cay A, Atrav R, Duran K (2007) Effects of warp-weft density variation and fabric porosity of the cotton fabrics on their colour in reactive dyeing. Fibres Text East Eur 1(60):91-94

28. Textile Learner https://textilelearner.blogspot.com/

Publisher's Note Springer Nature remains neutral with regard to jurisdictional claims in published maps and institutional affiliations. 